\title{
Enhancement of dissolution profile for oral delivery of Fexofenadine Hydrochloride by solid dispersion (solvent evaporation) technique
}

\author{
Sheikh Tasnim Jahan ${ }^{1}$, Md. Saifur Rahman Khan ${ }^{2}$, Md. Moniruzzaman ${ }^{1}$ \\ Md. Rezowanur Rahman ${ }^{1}$, Sams Mohammad Anowar Sadat ${ }^{1 *}$ and Reza-ul Jalil ${ }^{1}$ \\ 1 Department of Pharmaceutical Technology, Faculty of Pharmacy, University of Dhaka, \\ Dhaka-1000, Bangladesh. \\ ${ }^{2}$ Department of Mathematics and Natural Sciences, Brac University, Dhaka-1212, \\ Bangladesh.
}

\begin{abstract}
The objective of present work is to investigate the enhancement of dissolution profile for oral delivery of Fexofenadine Hydrochloride (FH) through solid dispersion (SD) technique by the method of solvent evaporation. The SD was prepared by using ethanol as a solvent. Tablets were formulated containing solid dispersion of $\mathrm{FH}$ and compared with tablets of same formula without solid dispersion of $\mathrm{FH}$. The using of ethanol to prepare solid dispersion found a significant effect on the dissolution of FH. Dissolution studies using the USP-33 paddle method were performed for tablets formulated with and without solid dispersions of $\mathrm{FH}$. Dissolution of $\mathrm{FH}$ improved significantly in tablets formulated with SD (85\% in 10 minutes) exhibited better dissolution profile than tablets formulated without SD. Infrared (IR) spectroscopy was also performed to identify the physicochemical interaction between drug and solvent, hence its effect on dissolution.
\end{abstract}

Keywords: Solid Dispersion, Fexofenadine Hydrochloride, Dissolution Enhancement.

\section{INTRODUCTION}

Fexofenadine Hydrochloride, a selective peripheral $\mathrm{H}_{1}$ receptor antagonist, is a potent antihistamine drug that is indicated for seasonal allergic rhinitis and chronic idiopathic urticaria (Vena et al., 2002). According to British Pharmacopoeia' 2009, it is slightly soluble in water. Its slight solubility makes its absorption, dissolution rate limited and thus delays onset of action. One of the major current challenges of pharmaceutical sciences is to enhancement of the solubility of poorly water soluble drugs.

Over the years, a number of techniques have been developed to improve the dissolution of poorly water soluble drugs, such as inclusion complexation, salt formation, and cogrinding (Anzai et al., 2007; Ki et al., 2007; Barzegar-Jalali et al., 2006). Among other techniques, solid dispersion (SD) is one of the popular methods to enhance the solubility and dissolution rate of poorly water soluble drugs (Pouton, 2006). In SD technique, the particle size of drugs is reduced from crystalline to microcrystalline or molecular state (Wang et al., 2005). This leads to the enhancement of the solubility.

To prepare SD of drug, there are three major methods as melting method, solvent method and solvent evaporation method. Among these three methods, melting method and solvent method have some drawbacks. Melting method requires high temperature which may result in the decomposition of drug. In solvent method, the issue of difficulty in selection of common volatile solvents arises coupled with chemical instability of drugs (Kim et al., 2006).

In this study, SD was prepared by solvent evaporation method without using any career. After assessing the drug content of the solid dispersion, the products were characterized by Infrared (IR) spectroscopy and in-vitro dissolution study.

\section{MATERIALS AND METHODS}

Materials: Fexofenadine Hydrochloride $(\mathrm{FH})$ was a gift sample from Id-swift Laboratories Itd, India. Microcrystalline Cellulose (Avicel PH 102) was purchased from Veer Pharma Chem, India. Sodium Starch Glycolate and Magnesium Stearate were supplied from Chemical Management Co., Germany.

\section{Methods}

Preparation of matrix tablets with SD of FH: Solid dispersion of $\mathrm{FH}$ was prepared by using solvent evaporation method. $\mathrm{FH}$ was dispersed in an appropriate amount of ethanol (2 times the total 
weight of drug). After smooth dispersion was prepared; it was transferred into a container. The solvent was evaporated at $45^{\circ} \mathrm{C}$ and resulting residue was dried in hot air oven for one hour and stored for 24 hours in a desiccators. Subsequently, the dispersion was passed through sieve no. 40. After sieving, this SD was mixed thoroughly with diluents
Microcrystalline Cellulose (Avicel PH 102) and disintegrating agents Sodium Starch Glycolate. Then the lubricant Magnesium Stearate was added to the powder mix and powder mix was passed through sieve no. 40 and mixed well. Then the powder mix is compressed using a Shimadzu laboratory hydraulic press equipped with $10 \mathrm{~mm}$ round punch, die set.

Table-1: Formulation of matrix tablets with SD of FH and without SD of FH.

\begin{tabular}{|c|c|c|}
\hline Formulation & F-1 (with SD) & F-2 (without SD) \\
\hline Fexofenadine $\mathrm{HCl}$ & $120 \mathrm{mg}$ & $120 \mathrm{mg}$ \\
\hline Avicel PH 102 & $170 \mathrm{mg}$ & $170 \mathrm{mg}$ \\
\hline Sodium Starch Glycolate & $8 \mathrm{mg}$ & $8 \mathrm{mg}$ \\
\hline Magnesium Stearate & $2 \mathrm{mg}$ & $2 \mathrm{mg}$ \\
\hline Total Weight & $300 \mathrm{mg}$ & $300 \mathrm{mg}$ \\
\hline
\end{tabular}

Preparation of matrix tablets without SD of FH: $\mathrm{FH}$ was mixed thoroughly with Microcrystalline Cellulose (Avicel PH 102), Sodium Starch Glycolate and Magnesium Stearate as well. The powder mix was passed through sieve no. 40 and mixed well. Then the powder mix is compressed using a Shimadzu laboratory hydraulic press equipped with $10 \mathrm{~mm}$ round punch, die set. The formulation of matrix tablets without SD of $\mathrm{FH}$ was termed as $\mathrm{F}-2$.

\section{Solid state studies}

Fourier Transform Infrared (FTIR) spectroscopy: FTIR spectra were recorded on samples prepared in potassium bromide $(\mathrm{KBr})$ discs using a Shimadzu FTIR 8000 series spectrophotometer (Tokyo, Japan). Samples were prepared in $\mathrm{KBr}$ discs by means of a hydrostatic press. The scanning range was from 400 $\mathrm{cm}^{-1}$ to $2000 \mathrm{~cm}^{-1}$ and the resolution was $4 \mathrm{~cm}^{-1}$.

In-vitro dissolution studies: Dissolution studies were performed in $900 \mathrm{ml} 0.001 \mathrm{~N} \mathrm{HCl}$ at $37 \pm 0.5^{\circ} \mathrm{C}$, using 6-station USP Electro Lab Tablet Dissolution Test Machine (XXII); with paddle rotating at $50 \mathrm{rpm}$. Products of both formulations (F-1 \& F-2), each containing $120 \mathrm{mg}$ of drug were subjected to dissolution. At fixed time intervals (after 10 and 30 minutes), samples withdrawn were filtered (pore size $0.22 \mu \mathrm{m}$ ) and spectrophotometrically assayed for drug content at $220 \mathrm{~nm}$ according to the dissolution procedure of United States Pharmacopoeia $\left(32^{\text {th }}\right.$ Edition).

Evaluation of tablets:The prepared matrix tablets were evaluated for weight variation, hardness, thickness, friability and drug content. Hardness of the tablets was tested using a strong-Cobb hardness tester (Tab-Machine, Mumbai). Friability of the tablets was determined in a Roche friabilator (Campbell Electronics, Mumbai). The thickness of the tablets was measured by vernier calipers. Weight variation test was performed according to the official method of British Pharmacopoeia. Drug content for $\mathrm{FH}$ was carried out according to assay procedure of United States Pharmacopoeia ( $32^{\text {th }}$ Edition).

\section{RESULTS AND DISCUSSION}

Fourier Transform Infrared (FTIR) spectroscopy: IR spectra of $\mathrm{FH}$ and its SD system were presented in Figure-1. Pure $\mathrm{FH}$ spectra showed sharp characteristic peaks at 1710, 1440, 1275, 1180, $1060,960,825,750$ and $705 \mathrm{~cm}^{-1}$. All the above characteristic peaks appear in the spectra of SD system at same wave number indicating no modification or interaction between the drug and solvent.

Physical parameters study: The results of physical parameters i.e. weight, hardness, thickness and friability as well as drug content of the prepared matrix tablets for both formulations was shown in Table-2. The hardness of tablets found ranges from $8.0 \pm 0.02 \mathrm{~kg} / \mathrm{cm}^{2}$ to $8.1 \pm 0.02 \mathrm{~kg} / \mathrm{cm}^{2}$ and friability ranges from $0.13 \%$ to $0.15 \%$ respectively. The tablet formulations in all the prepared batches contained $\mathrm{FH}$ within $94 \%$ to $100 \%$ of labeled content. All tablets complied with the specifications of pharmacopoeia standards for weight variation and friability. 
Am. J. Sci. Ind. Res., 2011, 2(1): 112-115

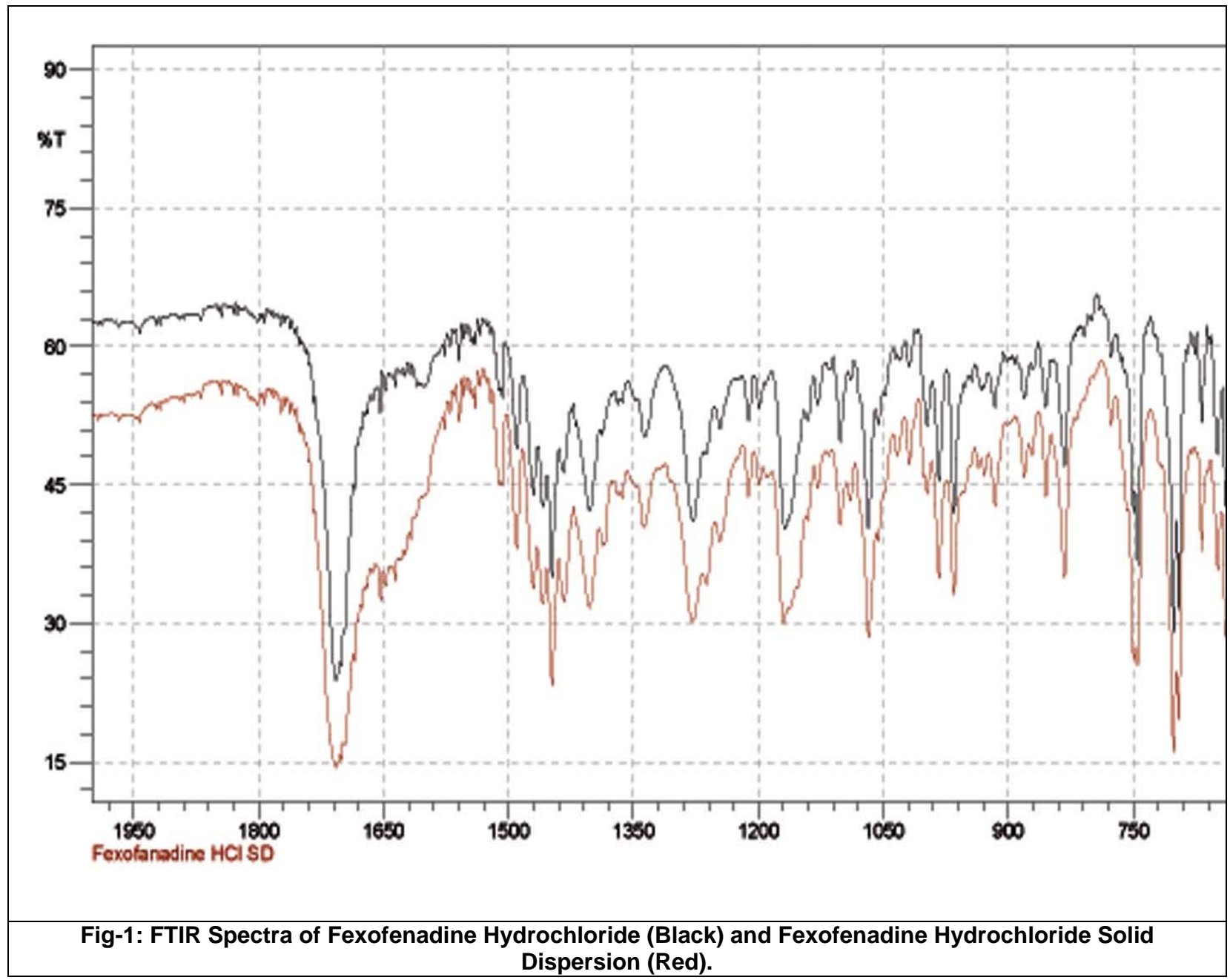

\begin{tabular}{|l|c|c|c|c|c|c|c|}
\hline \multicolumn{2}{|c|}{ Table-2: The results of physical parameters and drug content of two formulations. } \\
\hline Formula & $\begin{array}{c}\text { Weight } \\
(\mathrm{mg}) \\
\pm S \mathrm{SD}(\mathrm{n}=20)\end{array}$ & $\begin{array}{c}\text { Hardness } \\
\left(\mathrm{Kg} / \mathrm{cm}^{2}\right) \\
\pm \mathrm{SD}(\mathrm{n}=5)\end{array}$ & $\begin{array}{c}\text { Thickness }(\mathrm{mm}) \\
\pm \mathrm{SD}(\mathrm{n}=5)\end{array}$ & $\begin{array}{c}\text { Friability } \\
(\%)\end{array}$ & $\begin{array}{c}\text { Drug Content } \\
(\%) \\
\pm S D(n=5)\end{array}$ \\
\hline F-1 & $300.1 \pm 1.21$ & $8.1 \pm 0.22$ & $3.30 \pm 0.05$ & 0.15 & $94.37 \pm 0.57$ \\
\hline F-2 & $301.2 \pm 1.61$ & $8.0 \pm 0.30$ & $3.31 \pm 0.02$ & 0.13 & $99.24 \pm 0.53$ \\
\hline
\end{tabular}

In-vitro dissolution studies: Table-3 shows data analysis of release profiles at different time points (10 $\mathrm{min}, 30 \mathrm{~min})$. The drug release from $\mathrm{F}-1$ was over $85 \%$ after 10 minutes where drug release from $\mathrm{F}-2$, only $56.23 \%$ after 10 minutes. Sequentially drug release from $\mathrm{F}-1$ after 30 minutes was $96.91 \%$ which is higher than that of F-2, only $71.24 \%$. So the solid dispersion technique has improved the dissolution of $\mathrm{FH}$ from its matrix tablets to a greater extent.

The technique that has been useful in that dissolution of poorly water soluble drugs is the use of suitable volatile solvent to prepare SD of $\mathrm{FH}$. When solvent evaporates properly from the solid dispersion, the dispersed drug being lack of crystallinity i.e. amorphization, increased wettability as well as dispersibility and particle size reduction considered to be important factors for dissolution rate enhancement. Because dry mixing of SD with other excipients results in greater wetting and increases surface available for dissolution as it reduces the interfacial tension between hydrophobic drug and dissolution media. 
Am. J. Sci. Ind. Res., 2011, 2(1): 112-115

Table-3: In-vitro release profile of two formulations.

\begin{tabular}{|c|c|c|}
\hline Formula & After 10 minutes & After 30 minutes \\
\hline $\mathrm{F}-1$ & $88.29 \%$ & $96.91 \%$ \\
\hline $\mathrm{F}-2$ & $56.23 \%$ & $71.24 \%$ \\
\hline
\end{tabular}

\section{CONCLUSION}

This study shows that the dissolution rate of $\mathrm{FH}$ can be enhanced to a greater extent through solid dispersion by using an industrially feasible solvent evaporation technique. Hence this process can be considered for the formulation matrix tablet of various poorly water soluble drugs for rapid and high dissolution rate as well as high oral absorption and bioavailability.

\section{REFERENCES}

Anzai K, Mizoguchi J, Yanagi T, Hirayama F, Arima H, Uekama K. Improvement of dissolution properties of a new helicobacter pylori eradicating agent ( $\operatorname{tg} 44)$ by inclusion complexation with beta- cyclodextrin. Chem Pharm Bull (Tokyo) 2007; 55: 1466-70.

Barzegar-Jalali M, Nayebi AM, Valizadeh $H$, Hanaee J, Barzegar- Jalali A, Adibkia $\mathrm{K}$, et al. Evaluation of in vitro-in vivo correlation and anticonvulsive effect of carbamazepine after cogrinding with microcrystalline cellulose. J Pharm Sci. 2006; 9: 307-16.
Ki HM, Choi HK. The effect of meloxicam/ethanolamine salt formation on percutaneous absorption of meloxicam. Arch Pharm Res 2007; 30: 215-21.

Kim EJ, Chun MK, Jang JS, Lee IH, Lee KR, Choi HK. Preparation of a solid dispersion of felodipine using a solvent wetting method. Eur J Pharm Biopharm. 2006; 64: $200-5$.

Pouton CW. Formulation of poorly water-soluble drugs for oral administration: Physicochemical and physiological issues and the lipid formulation classification systems. Eur J Pharm Sci. 2006; 29: 278-87.

Vena GA, Cassano N, Filieri M, Filotico R, D'Argento V, Coviello C (2002). "Fexofenadine in chronic idiopathic urticaria: a clinical and immunohistochemical evaluation". International Journal of Immunopathology and Pharmacology. 15(3): 217-224.

Wang L, Cui FD, Hayase T, Sunada H. Preparation and evaluation of solid dispersion for nitrendipine-carbopol and nitrendipine-hpmcp systems using a twin screw extruder. Chem Pharm Bull (Tokyo)2005;53:1240-5. 